\title{
STUDY ON SUPERSONIC CONDENSATION AND INFLUENCING FACTORS OF NATURAL GAS WITH CARBON DIOXIDE
}

\author{
Rongge Xiao a,*, Shuaishuai Jin ${ }^{\mathrm{a}}$, Xin Feng ${ }^{\mathrm{b}}$, Peng Zhang ${ }^{\mathrm{c}}$, Zheng Dai ${ }^{\mathrm{c}}$ \\ ${ }^{a}$ Shaanxi Key Laboratory of Advanced Stimulation Technology for Oil \& Gas Reservoirs, College of Petroleum Engineering, Xi'an Shiyou \\ University, Xian 710065, Shaanxi China; \\ ${ }^{b}$ PetroChina Changqing Oilfield Company, Xi'an 710016, China \\ ${ }^{c}$ Xi'an Northwest Oil Pipeline Co. Ltd. Xian 710016, Shaanxi, China
}

\begin{abstract}
With the increasing production and use of natural gas, the supersonic nozzle has become focus of the impurity removal research. In this paper, the modified classical nucleation model is used as the condensation nucleation model, and the Gyarmathy growth model is selected as the droplet growth model. Based on the assumption of no phase slip and Eulerian two fluid model, the flow control equation of wet natural gas is established. By giving the selection criteria as a turbulence equation, the SRK real gas equation is used to carry out the corresponding numerical simulation. The required supersonic nozzle structure and grid number are designed and verified. On basis of the above, the variation of temperature, pressure, nucleation rate, humidity and nucleation rate with the distance $\mathrm{X}$ of the nozzle after the methane-carbon dioxide gas enters the nozzle is studied, and the effects of different temperature, pressure and gas component proportion on droplet number, humidity and nucleation rate are explored.
\end{abstract}

Key words: Carbon dioxide, Wet natural gas, Supersonic, Condensation law, Numerical simulation

Due to the advantages of cleanness, high calorific value, and easy transportation after liquefaction, natural gas has gradually become the first choice for energy consumption in most countries in the world (Kumar, et al., 2011; Wang, et al., 2017). Natural gas is a mixture of hydrocarbons and contains a few non-hydrocarbon impurities, and some of these impurities will bring hidden dangers during the transportation of natural gas pipelines. With continuous increase of the pipeline transmission distance, temperature of the transmission medium will decrease, water vapor contained in the natural gas will condense, and hydrogen sulfide and carbon dioxide will dissolve into the condensed water, providing conditions for the acid gas hydrogen sulfide and carbon dioxide to corrode the metal pipeline (Fan, et al., 2008), thereby causing corrosion of the conveying equipment. In addition, the water condensed under certain conditions will form natural gas hydrates with natural gas, block pipelines and instrumentation, and reduce the efficiency of pipeline transportation, resulting in failure to meet the transmission requirements (Zhang, et al., 2000). Therefore, it is very necessary to separate water, acid gas and heavy hydrocarbons in the natural gas. However, with the substantial growth of natural gas production and demand, the traditional natural gas impurity removal technology has been unable to meet the continuous development of the natural gas market due to some reasons; hence a new impurity removal technology came into being. This new technology performs dehydration and deacidification by taking advantage of the high-speed natural gas expansion and cooling characteristics, and the method of hydrocyclone separation after condensation (Cao, et al., 2019; Song, et al., 2010). Therefore, study of the condensed flow law of supersonic natural gas in the supersonic nozzle and analysis of the condensed flow process mechanism are the basis and key to dehydration and deacidification of this technology.

At present, scholars have mainly conducting research on condensation flow of single-component gas and two-component gas (Yang, et al., 2008; Jiang, et al., 2010; Wang, et al., 2012; Cao, et al., 2019), and analyzing and demonstrating the application effect of the technology in dehydration. However, as a hydrocarbon mixture, natural gas contains many components, and different gas components have a significant influence on the condensation process. That is why in-depth understanding of the condensate flow law of two-component gas has important theoretical value and guiding significance for application of this technology on separation of impurities in natural gas. Therefore, methane-carbon dioxide is used as the research medium for the supersonic condensation characteristics of natural gas containing carbon dioxide in this paper. Based on previous research, the condensation law of two-component gas in the supersonic nozzle is analyzed and studied; The distribution law of key parameters such as temperature, pressure, droplet number, humidity, and nucleation rate is explored; and the influencing factors of inlet pressure, inlet temperature, and gas composition proportion changes are also studied. This will provide some references for subsequent research on supersonic flow and condensation law of methane-steam-carbon dioxide three-component gas in the nozzle.

\section{SUPERSONIC CONDENSATION FLOW MODEL}

Condensation nucleation model (Bian, et al., 2019) see equation (1), Gyarmathy droplet growth model (Gyarmathy, et al., 1962) see equation (2), flow control equations (Sun, et al., 2017) see equation (3) - (14), standard $k-\varepsilon$ turbulence model see equation (15) and (16), SRK real gas equation ( $\mathrm{Li}$, et al., 2002) see equation (17):

$J=K \times \exp \left(-\frac{\Delta G}{k_{B} T_{v}}\right)$

\footnotetext{
* Corresponding Author. E-mail: xiaorongge@163.com.
} 


$$
\frac{d r}{d t}=\frac{\lambda_{v}\left(1-\frac{r_{c}}{r}\right)\left(T_{s}-T_{v}\right)}{\rho_{l} h_{l v}\left(r+\frac{2 \sqrt{8 \pi}}{1.5 P_{r v}} \frac{\gamma}{\gamma+1} \mathrm{Kn}\right)}
$$

Assuming that there is no slip between the two phases of gas and liquid, the following equation could be established on the basis of the Eulerian two fluid model:

$$
\begin{aligned}
& \frac{\partial \rho_{v}}{\partial t}+\frac{\partial}{\partial x_{j}}\left(\rho_{v} u_{j}\right)=S_{m} \\
& \frac{\partial \rho_{c}}{\partial t}+\frac{\partial}{\partial x_{j}}\left(\rho_{\mathrm{c}} u_{j}\right)=S_{\mathrm{m}} \\
& \frac{\partial}{\partial t}\left(\rho_{v} u_{i}\right)+\frac{\partial}{\partial x_{j}}\left(\rho_{v} u_{j} u_{i}\right)=-\frac{\partial p}{\partial x_{i}}+ \\
& \frac{\partial}{\partial x_{j}}\left[\mu\left(\frac{\partial u_{i}}{\partial x_{j}}+\frac{\partial u_{j}}{\partial x_{j}}-\frac{2}{3} \delta_{i j} \frac{\partial u_{j}}{\partial x_{j}}\right)\right] \\
& \frac{\partial}{\partial t}\left(\rho_{v} E\right)+\frac{\partial}{\partial x_{j}}\left(\rho_{v} u_{j} E+u_{j} p\right)= \\
& \frac{\partial}{\partial x_{j}}\left(k_{e f f} \frac{\partial T}{\partial x_{j}}+u_{i} \tau_{e f f}\right)+S_{h} \\
& \frac{\partial}{\partial t}(\rho Y)+\frac{\partial}{\partial x_{j}}\left(\rho u_{j} Y\right)=S_{\mathrm{Y}} \\
& r=\left[3 Y /\left(4 \pi \rho_{1} N\right)\right]^{\frac{1}{3}} \\
& \frac{\partial \rho N}{\partial t}+\frac{\partial}{\partial x_{j}}\left(\rho N u_{j}\right)=\mathrm{J} \\
& S_{m}=-m \\
& S_{u}=-m u_{i} \\
& S_{h}=m\left(\mathrm{~h}_{1 v}-\mathrm{h}\right) \\
& S_{Y}=m \\
& m=J \rho_{1} \frac{4 \pi r_{c}^{3}}{3}+4 N \rho_{v} \rho_{1} \pi r^{2} \frac{d r}{d t} \\
& \frac{\partial(\rho k)}{\partial t}+\frac{\partial\left(\rho k u_{i}\right)}{\partial x_{i}}=\frac{\partial}{\partial x_{j}}\left[\left(\mu+\frac{\mu_{t}}{\sigma_{k}}\right) \frac{\partial_{k}}{\partial x_{j}}\right] \\
& +G_{k}+G_{b}-\rho \varepsilon-Y_{M}+S_{k} \\
& \frac{\partial(\rho \varepsilon)}{\partial t}+\frac{\partial\left(\rho \varepsilon u_{i}\right)}{\partial x_{i}}=\frac{\partial}{\partial x_{j}}\left[\left(\mu+\frac{\mu_{t}}{\sigma_{\varepsilon}}\right) \frac{\partial \varepsilon}{\partial x_{j}}\right] \\
& +C_{1 \varepsilon} \frac{\varepsilon}{k}\left(G k+C_{3 \varepsilon} G_{b}\right)-C_{2 \varepsilon} \rho \frac{\varepsilon^{2}}{k}+S_{\varepsilon} \\
& p=\frac{R T}{V-b}-\frac{a(T)}{V(V+b)}
\end{aligned}
$$

\section{DESIGN AND VERIFICATION OF SUPERSONIC NOZZLE}

2.1 Structure design of supersonic nozzleesults

Since 2D nozzle structure can also display the gas condensation law well, and its calculation speed is faster than $3 \mathrm{D}$, according to the previous design experience ( $\mathrm{Xu}$, et al., 2015; Wang, et al., 2006), we assumed that the gas inlet pressure is $6 \mathrm{MPa}$, the inlet temperature is $273.15 \mathrm{~K}$ and outlet Mach number is 1.5 . The 2D supersonic nozzle structure required for this study is designed and its schematic diagram is shown in Fig. 1 (The abscissa $X$ represents the nozzle symmetry axis, and the ordinate $\mathrm{Y}$ is the radius of each part of the nozzle). Nozzle structure data is shown in Tab. 1.

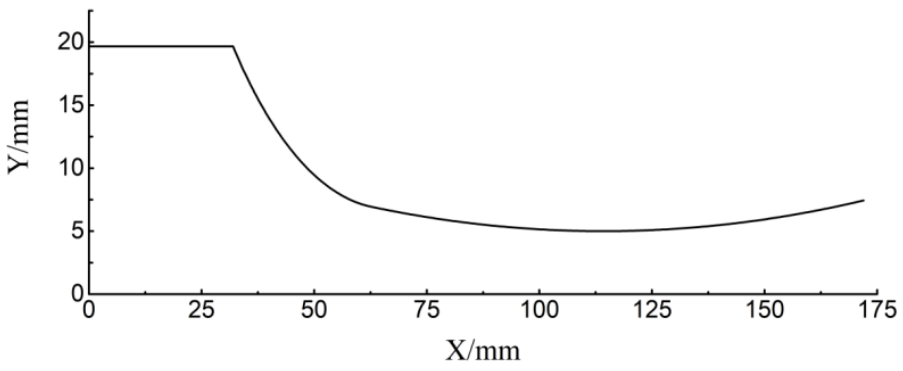

Fig.1 Schematic diagram of nozzle structure

\subsection{Rationality verification of supersonic nozzle}

When the gas does not condense, the irrational nozzle structure will generate shock waves somewhere in the expansion section of the nozzle. Since shock wave will cause rising of temperature and pressure, it is necessary to analyze rationality of the designed nozzle structure before studying condensation law of methane-carbon dioxide two-component gas. If the gas does not condense in the nozzle, temperature and pressure of the gas in the nozzle will not increase. In this section, the verification analysis is carried out with methane-carbon dioxide twocomponent gas. The temperature and pressure cloud picture in the nozzle are shown in Fig. 2 (a) and (b) below.

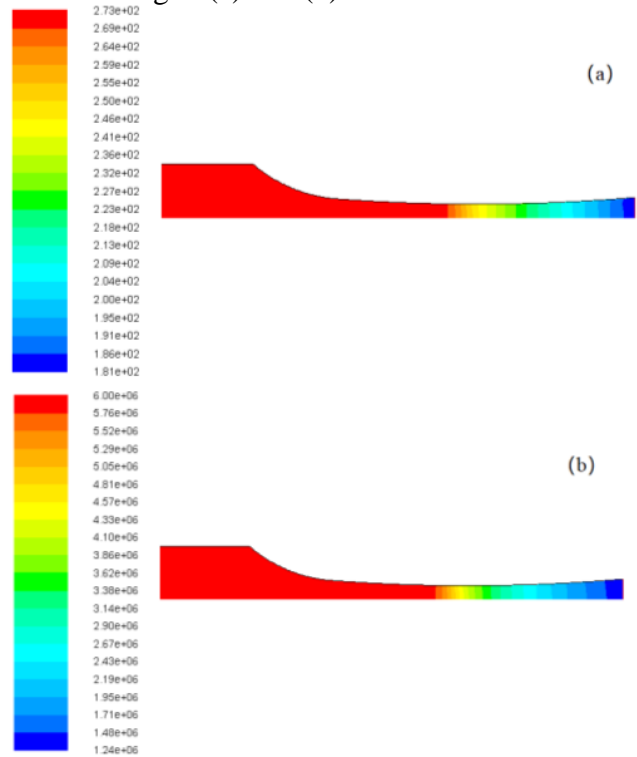

Fig. 2 Temperature and pressure nephogram in nozzle

It can be seen from the observation above that the temperature and pressure increase did not occur when methane and carbon dioxide gas in the supersonic nozzle is not condensed, which shows that the designed nozzle structure is rational and can be used for subsequent numerical simulation.

\subsection{Grid independence verification of supersonic nozzle}

In order to make the numerical simulation research unaffected by grid number, it is necessary to verify the independence of the supersonic nozzle grid before conducting the research. Before conducting this numerical simulation study, four nozzle models with different grid 
numbers were divided and imported into Fluent software, and related simulations were carried out under the same working conditions. By doing this, data of droplet number, humidity and nucleation rate at the nozzle axis under different grid numbers are compared, and the relative error was calculated based on the data, as shown in Tab. 2 .

It can be seen from Tab. 2 that the nozzle models with grid numbers of $28435,32574,37642$ and 42138 were used to verify the grid independence in this paper. We selected the nozzle model with 37642 grids. Based on its data, we had calculated the changes of each key parameter when grid number increased or decreased. It can be seen from the above table that the calculation results of different grid numbers are very close to calculation results of the reference grids 37642 , and no clear changes have occurred. Therefore, the irrelevance of the supersonic nozzle grid was also proved, the nozzle grid with grids number 37642 could be used for subsequent numerical simulation research.

\section{STUDY ON THE SUPERSONIC CONDENSATION LAW OF METHANE-CARBON DIOXIDE GAS}

In this section, a two-component methane-carbon dioxide gas was used to conduct a numerical simulation under the conditions of temperature $273.15 \mathrm{~K}$, pressure of $6 \mathrm{MPa}$, and carbon dioxide molar component 0.2. The cloud pictures of temperature, pressure, droplet number, humidity and nucleation rate are shown in Fig. 3 (a), (b), (c), (d) and (e) as follows.

Fig. 3 (a) and (b) shows gas temperature and pressure changes in the nozzle respectively. It can be seen that the temperature and pressure had been decreasing from the nozzle inlet to a certain distance, and then suddenly increased. This was because the gas has condensed somewhere away from the throat, and the heat released by condensation had caused rise of temperature and pressure. But after this, the gas was still in the expansion process, so the temperature and pressure continue to fall; Fig. 3 (c), (d) and (e) describes changing process of the droplet number, humidity and nucleation rate in the nozzle respectively. It can be seen that there was no change from the nozzle inlet to a certain distance, but after a period of time, the gas had condensed somewhere away from the throat, the nucleation rate began to increase in an instant, the number of condensation nucleus began to increase, and the droplet number also increased. When the radius of the condensation core reached the critical radius, the droplets began to grow rapidly and the humidity increased. After that, temperature and pressure increased due to exothermic heat from gas liquefaction, and the nucleation rate dropped to 0 , the condensation nucleus was no longer generated. In this case the droplet number no longer changed, but the humidity continued to increase because the droplets continued to grow.

\section{STUDY ON FACTORS INFLUENCING SUPERSONIC CONDENSATION OF METHANE-CARBON DIOXIDE GAS}

\subsection{Influence of inlet pressure}

In this section, a numerical simulation study was conducted under conditions of temperature $273.15 \mathrm{~K}$ and carbon dioxide mole fraction 0.2 to explore the influence of different inlet pressures on the droplet number, humidity, and nucleation rate. The curve of droplet number change generated at the gas axis in the nozzle under different pressures is shown in Fig. 4 (a), and the curve of humidity change at the gas axis in the nozzle under different pressures is shown in Fig. 4 (b). The curve of nucleation rate at the gas axis in the nozzle under different pressures is shown in Fig. 4 (c).

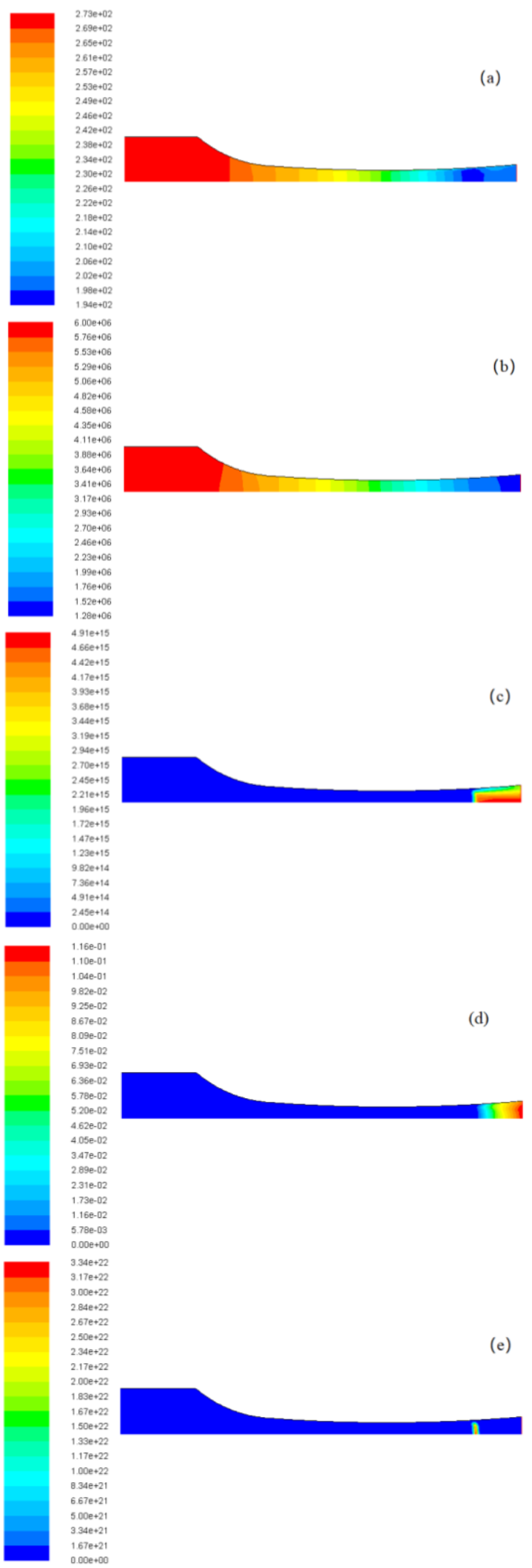

Fig. 3 Cloud chart of each parameter in nozzle 

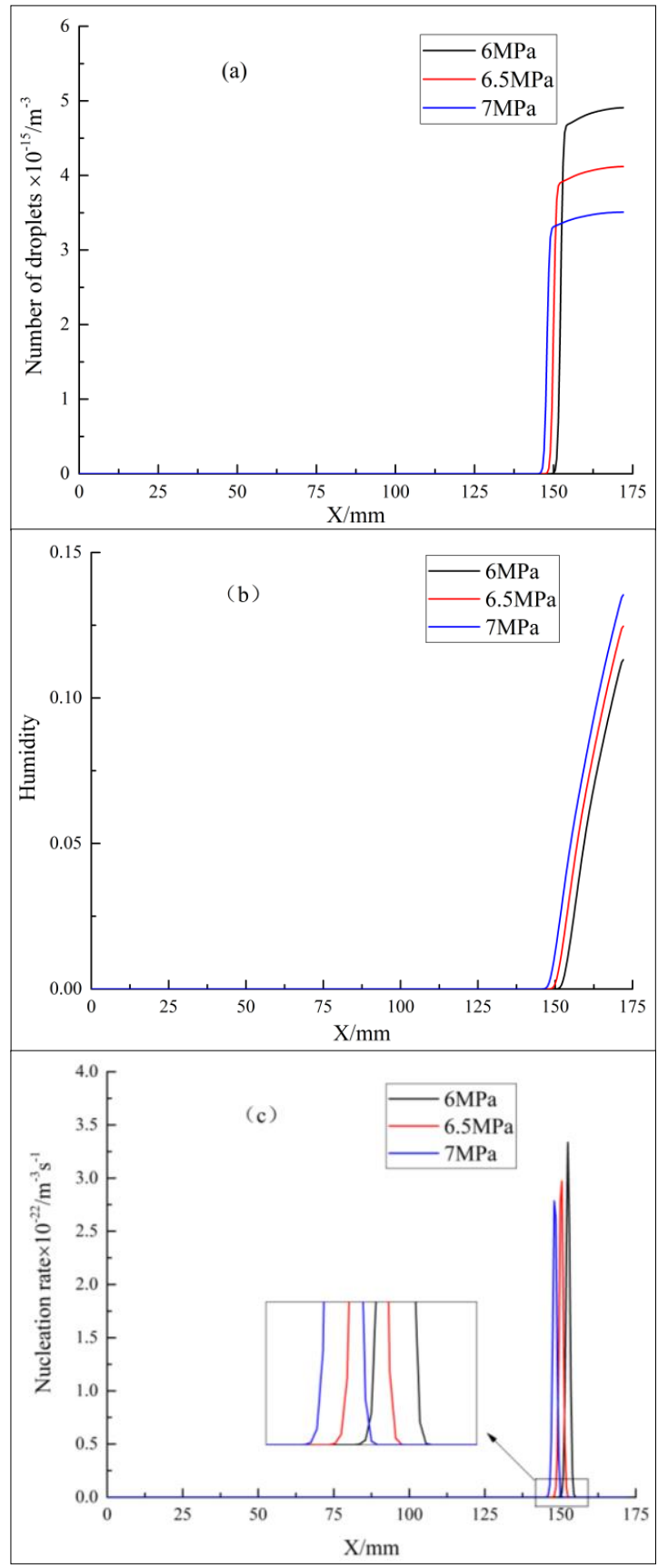

Fig.4 The influence of inlet pressure on the variation of parameters

It can be seen from Fig. 4 (a) that when the pressure was $6 \mathrm{MPa}$, the droplet number was always 0 when nozzle distance was less than $\mathrm{X}=150 \mathrm{~mm}$, after which it increased rapidly until reached to $4.91 \times 10^{15} \mathrm{~m}^{-3}$ at the nozzle outlet, and kept it approximately constant. As the pressure increased, position of the gas generated droplets at axis of the nozzle continue to move forward, the droplet number eventually generated at the nozzle outlet decreased, and the value of droplet number remained approximately constant.

It can be seen from Fig. 4 (b) that when the pressure was $6 \mathrm{MPa}$, the humidity was always 0 when the nozzle distance was less than $\mathrm{X}=150 \mathrm{~mm}$, after which it increased rapidly and reached to 0.116 at the nozzle outlet. As the pressure increased, humidity increase position at axis of the nozzle continued to move forward, and the humidity increased at the nozzle outlet.

It can be seen from Fig. 4 (c) that when the pressure was $6 \mathrm{MPa}$, the nucleation rate was always 0 when nozzle distance was less than $\mathrm{X}=150 \mathrm{~mm}$, after which it increased rapidly. When it reached to about $X=152.5 \mathrm{~mm}$, it increased to a peak of $3.34 \times 10^{22} \mathrm{~m}^{-3} \mathrm{~s}^{-1}$ and then decrease rapidly. It finally fell to 0 when $X=155 \mathrm{~mm}$. As the pressure increased, position of gas nucleation rate growth and position of the peak at the axis of the nozzle continued to move forward, the peak of the nucleation rate decreased, and the nucleation rate dropped to 0 later.

\subsection{Influence of inlet temperature}

In this section, a numerical simulation study was conducted under the conditions of $6 \mathrm{MPa}$ pressure and 0.2 carbon dioxide mole fraction, to explore the influence of different inlet temperatures on droplet number, humidity, and nucleation rate. The curve of droplet number change generated at the gas axis in the nozzle under different temperatures is shown in Fig. 5 (a), and the curve of humidity change at the gas axis in the nozzle under different temperatures is shown in Fig. 5 (b). The curve of nucleation rate at the gas axis in the nozzle under different temperatures is shown in Fig. 5 (c):
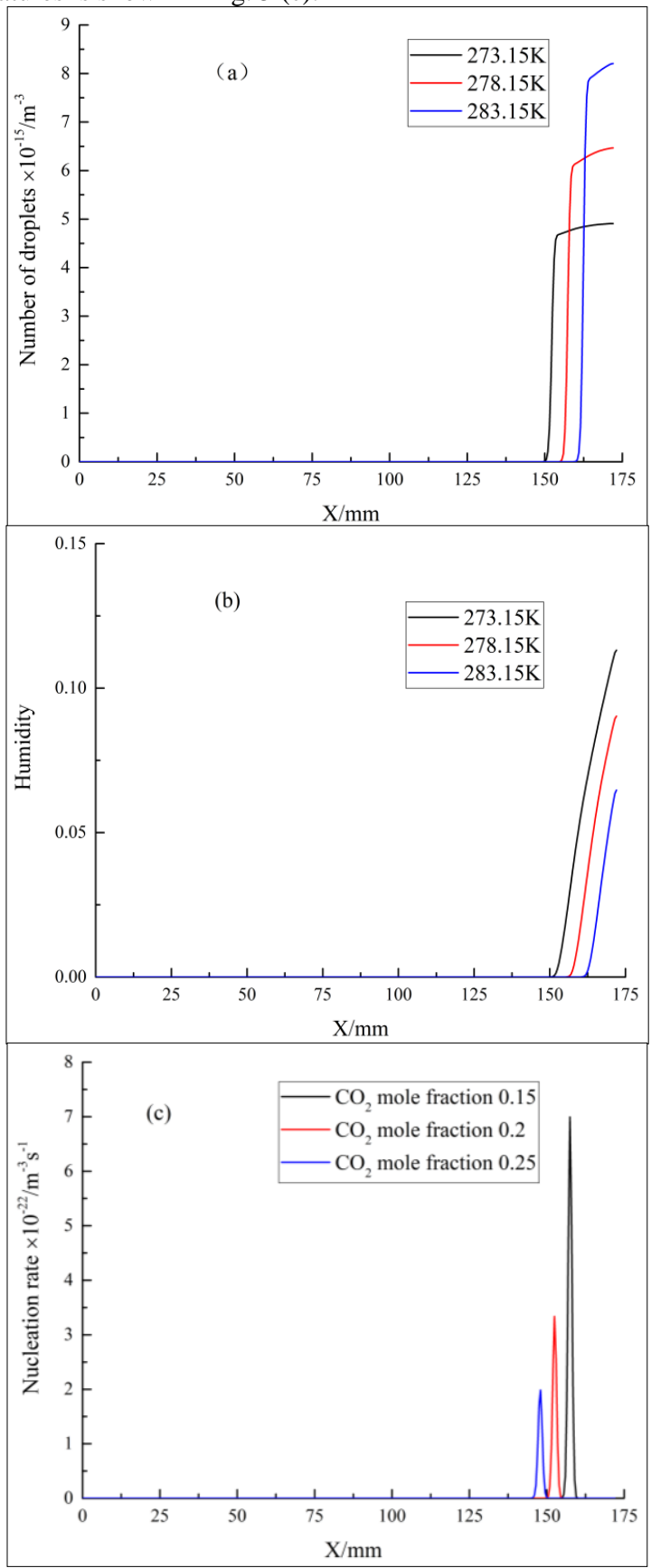

Fig.5 The influence of inlet temperature on the variation of parameters

It can be seen from Fig. 5 (a) that when the temperature was $273.15 \mathrm{~K}$, the droplet number was always 0 when nozzle distance was less than $X=150 \mathrm{~mm}$, after which it increased rapidly until reached to $4.91 \times 10^{15} \mathrm{~m}^{-3}$ at the nozzle outlet, and kept it approximately constant. As the temperature increased, position of the gas generates droplets at 
axis of the nozzle continued to move backward, the droplet number eventually generated at the nozzle outlet increased, and the value of droplet number remained approximately constant.

It can be seen from Fig. 5 (b) that when the temperature was $273.15 \mathrm{~K}$, the humidity was always 0 when the nozzle distance was less than $\mathrm{X}=150 \mathrm{~mm}$, after which it increased rapidly and reached to 0.116 at the nozzle outlet. As the temperature increased, humidity increase position at axis of the nozzle continued to move backward, and the humidity decreased at the nozzle outlet.

It can be seen from Fig. 5 (c) that when the temperature was $273.15 \mathrm{~K}$, the nucleation rate was always 0 when nozzle distance was less than $X=150 \mathrm{~mm}$, after which it increased rapidly. When it reached to about $X=152.5 \mathrm{~mm}$, it increased to a peak of $3.34 \times 10^{22} \mathrm{~m}^{-3} \mathrm{~s}^{-1}$ and then decreased rapidly. It finally fell to 0 when $X=155 \mathrm{~mm}$. As the pressure increased, position of gas nucleation rate growth and position of the peak at the axis of the nozzle continued to move backward, the peak of the nucleation rate increased, and the nucleation rate dropped to 0 later.

\subsection{Influence of gas composition proportion}

In this section, a numerical simulation study was conducted under the conditions of temperature of $273.15 \mathrm{~K}$ and pressure of $6 \mathrm{MPa}$ to explore the influence of different gas composition proportion on the droplet number, humidity, and nucleation rate. The curve of droplet number change generated at the gas axis in the nozzle under different gas composition proportion is shown in Fig. 6 (a), and the curve of humidity change at the gas axis in the nozzle under different gas composition proportion is shown in Fig. 6 (b). The curve of nucleation rate at the gas axis in the nozzle under different gas composition proportion is shown in Fig. 6 (c):

It can be seen from Fig. 6 (a) that when the carbon dioxide mole fraction was 0.15 , the droplet number was always 0 when nozzle distance was less than $X=154.5 \mathrm{~mm}$, after which it increased rapidly and reached to $11 \times 10^{15} \mathrm{~m}^{-3}$ at the nozzle outlet, and kept it approximately constant. As the carbon dioxide mole component increased, position of the gas generates droplets at axis of the nozzle continued to move forward, the droplet number eventually generated at the nozzle outlet decreased, and the value of droplet number remained approximately constant.

It can be seen from Fig. 6 (b) that when the carbon dioxide mole fraction was 0.15 , the humidity was always 0 when the nozzle distance was less than $X=154.5 \mathrm{~mm}$, after which it increased rapidly and reached to 0.094 at the nozzle outlet. As the carbon dioxide mole component increased, humidity increase position at axis of the nozzle continued to move forward, and the humidity increased at the nozzle outlet.

It can be seen from Fig. 6 (c) that when the carbon dioxide mole fraction was 0.15 , the nucleation rate is always 0 when nozzle distance was less than $X=155 \mathrm{~mm}$, after which it increased rapidly. When it reached to about $X=157.5 \mathrm{~mm}$, it increased to a peak of $7 \times 10^{22} \mathrm{~m}^{-3} \mathrm{~s}^{-1}$ and then decreased rapidly. It finally fell to 0 when $X=160 \mathrm{~mm}$. As the carbon dioxide mole component increased, position of gas nucleation rate growth and position of the peak at the axis of the nozzle continued to move forward, the peak of the nucleation rate decreased, and the nucleation rate dropped to 0 later.

\section{CONCLUSIONS}

(1) In the supersonic nozzle, the gas temperature and pressure remain unchanged for a certain distance. With distance increase on nozzle $\mathrm{X}$ axis, these two items began to gradually decrease. Temperature would drop to the minimum at a certain distance from the throat, and then gradually increased and rose to the maximum at a distance from the throat, then began to gradually decrease again.

(2) When gas entering the nozzle from inlet to a distance to the throat, the droplet number, humidity, and nucleation rate did not increase. With distance increase of the nozzle $\mathrm{X}$ axis, the droplet number, humidity and nucleation rate began to increase, and the droplet number remained approximately constant at the outlet;
(3) The droplet number and the position of droplets appear would increase and move backward as the temperature increased; decrease and move forward as the pressure increased; and decrease and move forward as the mole fraction of condensable gas components increased. Humidity and the humidity increase position would decrease and move backward as the temperature increased; increase and move forward as the pressure increased, and increase and move forward as the mole fraction of condensable gas components increased. The nucleation rate peak and nucleation rate increase position would increase and move backward with temperature increase, decrease and move forward with pressure increase, and decrease and move forward with increase of mole fraction of the condensable gas components.
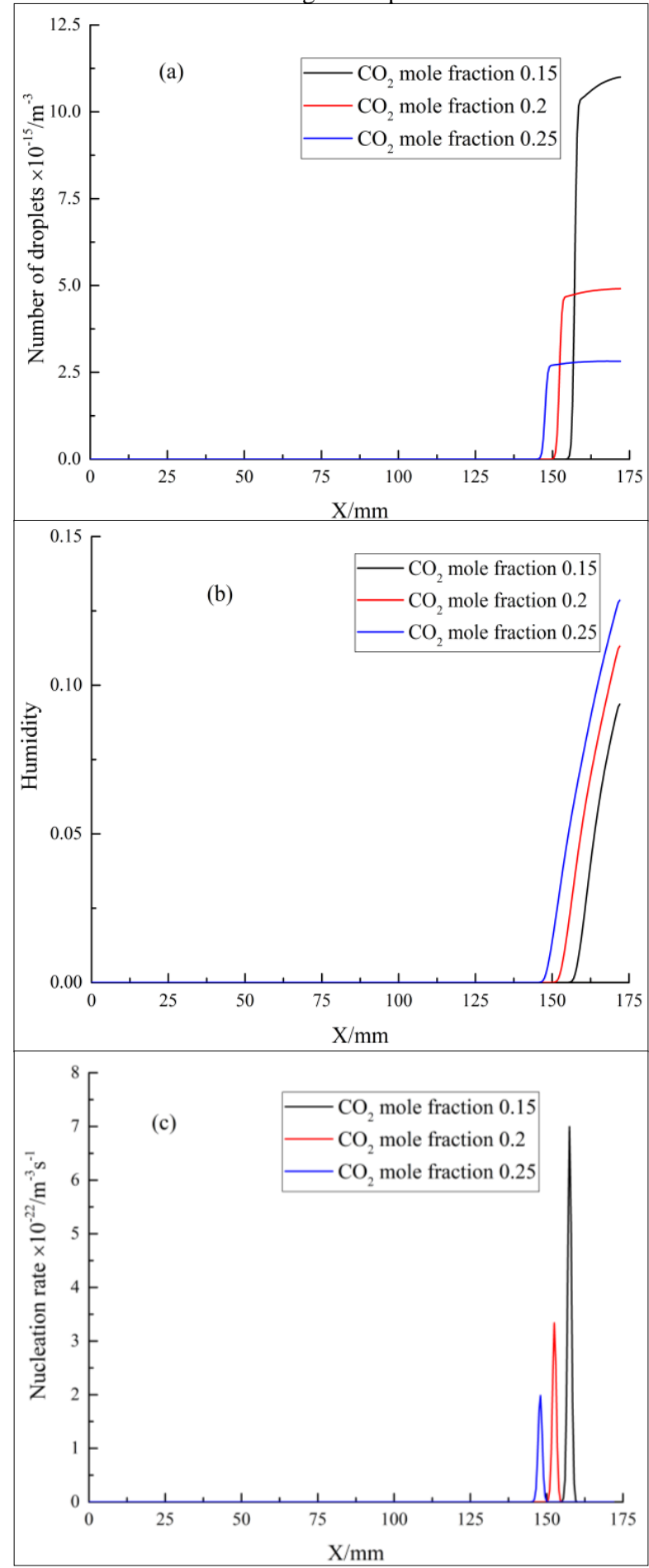

Fig.6 The influence of gas composition proportion on the variation of parameters 
Table 1 Nozzle structure parameters

\begin{tabular}{|c|c|c|c|}
\hline Length of stable section & $32.00 \mathrm{~mm}$ & Nozzle inlet radius & $19.67 \mathrm{~mm}$ \\
\hline Length of contraction section & $81.96 \mathrm{~mm}$ & Throat radius & $5.00 \mathrm{~mm}$ \\
\hline Length of expansion section & $58.03 \mathrm{~mm}$ & Nozzle exit radius & $7.44 \mathrm{~mm}$ \\
\hline
\end{tabular}

Table 2 Error of condensation parameters under different grid numbers

\begin{tabular}{|c|c|c|c|c|c|c|}
\hline $\begin{array}{c}\text { Number of } \\
\text { grids }\end{array}$ & $\begin{array}{c}\text { Number of droplets } \\
\left(\times 10^{15}\right)\end{array}$ & Error & Humidity & Error & $\begin{array}{c}\text { Nucleation rate } \\
\left(\times 10^{22} \mathrm{~m}^{-3} \mathrm{~s}^{-1}\right)\end{array}$ \\
\hline 28435 & 4.84 & $-1.5 \%$ & 0.1106 & $0.5 \%$ & 3.396 \\
\hline 32574 & 4.88 & $-0.6 \%$ & 0.1102 & $0.2 \%$ & 3.322 \\
\hline 37642 & 4.91 & -- & 0.1100 & -- & $-0.53 \%$ \\
\hline 42138 & 4.92 & $0.2 \%$ & 0.1080 & $-1.5 \%$ & -3.340 \\
\hline
\end{tabular}

\section{ACKNOWLEDGE}

This work was supported by the Special Funding Project of Shaanxi Provincial Department of Education 2019 Annual Service for Local Science Research Project(NO.19JC034), Xi'an Petroleum University Youth Science and Technology Innovation Fund (NO. 2015BS11), so grateful here.

\section{NOMENCLATURE}

$J$-nucleation rate per unit volume per unit time, $\mathrm{m}^{-3} \cdot \mathrm{s}^{-1}$;

$K$-kinetic prefactor;

$\Delta G$-energy barrier;

$k_{B}-$ Boltzmann constant, $k_{B}=1.38 \times 10^{-23} \mathrm{~J} / \mathrm{K}$;

$\lambda_{v}$-thermal conductivity of the vapor, $\mathrm{W} /(\mathrm{m} \cdot \mathrm{K})$;

$T_{s}$-saturation temperature of vapor, $\mathrm{K}$;

$P r_{v}$-Prandtl number;

$\gamma$ ratio of specific heats;

$K_{n}$-Knudsen number;

$\rho$-density, $\mathrm{kg} / \mathrm{m}^{3}$;

$\rho_{l}$-Liquid density, $\mathrm{kg} / \mathrm{m}^{3}$;

$\rho_{\nu}-$ Gas density, $\mathrm{kg} / \mathrm{m}^{3}$;

$\rho_{c}-\mathrm{CO}_{2}$ density, $\mathrm{kg} / \mathrm{m}^{3}$;

$h$-vapor total enthalpy, $\mathrm{J} / \mathrm{kg}$;

$h_{l v}$ - latent heat of condensation, $\mathrm{J} / \mathrm{kg}$;

$\mathrm{N}$-droplets number density, $\mathrm{kg}^{-1}$;

$m$-condensation mass per unit vapor volume per unit time, $\mathrm{kg} /$

$\left(\mathrm{m}^{3} \cdot \mathrm{s}\right)$;

$r$-droplet radius, $\mathrm{m}$;

$r_{c}$ —critical radius, $\mathrm{m}$;

$t$-time, $\mathrm{s}$;

$p$-pressure, $\mathrm{Pa}$;

$T$-temperature, $\mathrm{K}$;

$Y$ - mass fraction of condensed liquid;

$x_{i}, x_{j}-$ Axial and radial position coordinates, $\mathrm{m}$;

$u_{i}, u_{j}-$ Axial and radial velocity, $\mathrm{m} / \mathrm{s}$;

$u_{i}$ '、 $u_{j}{ }^{\prime}$-Axial and radial velocity fluctuations, $\mathrm{m} / \mathrm{s}$;

$S_{m}$ - source term of vapor continuity equation, $\mathrm{kg} /\left(\mathrm{m}^{3} \cdot \mathrm{s}\right)$;

$S_{u}$ - source term of vapor momentum equation, $\mathrm{kg} /\left(\mathrm{m}^{2} \cdot \mathrm{s}^{2}\right)$;

$S_{h}$ - source term of vapor energy equation, $\mathrm{kg} /\left(\mathrm{m}^{3} \cdot \mathrm{s}\right)$;

$S_{Y}$ - source term of liquid continuity equation, $\mathrm{kg} /\left(\mathrm{m}^{3} \cdot \mathrm{s}\right)$;

$E$ - total energy, $\mathrm{J} / \mathrm{kg}$;

$k_{\text {eff }}$ effective thermal conductivity, $\mathrm{W} /(\mathrm{m} \cdot \mathrm{K})$;

$\tau_{e f f}$ effective viscous stress;

$G_{k}$-The generation of turbulent kinetic energy caused by average velocity gradient;

$G_{b}$ - The generation of turbulent kinetic energy caused by buoyancy;

$Y_{M}$ - The effect of fluctuating expansion of compressible turbulence on the total dissipation rate;
$C_{1 \varepsilon}, C_{2 \varepsilon}, C_{3 \varepsilon}-$ Empirical constants, which can be respectively 1.44, $1.92,0.09$.

\section{REFERENCES}

Kumar S., Kwon H T., and Choi K H., 2011 "LNG: An eco-friendly cryogenic fuel for sustainable development." Applied Energy, 88(12):4264-4273.

https://doi.org/10.1016/j.apenergy.2011.06.035

Wang, Z., and Xue, Q., 2017 "To fully exert the important role of natural gas in building a modern energy security system in China: An understanding of China's National 13th Five-Year Plan for Natural Gas Development." Natural Gas Industry, 37(3) https://doi.org/10.3787/j.issn.1000-0976.2017.03.001

Fan, ZT., Yuan, ZM., and Liu, Jia., 2008. "Corrosion Mechanism and Protection Research of $\mathrm{H} 2 \mathrm{~S}$ and $\mathrm{CO} 2$ on Pipeline" Oil-Gas Field Surface Engineering, 27(10):39-40.

https://doi.org/10.3969/j.issn.1006-6896.2008.10.021.

Zhang, P., and Gong, J., 2000 "Preliminary Analysis on Hydrate Forming Conditions of Gas Transmission Pipeline" Oil \& Gas Storage and Transportion, 19(8):10-13

https://doi.org/10.3969/j.issn.1000-8241-D.2000.08.003.

Cao, XW., and Bian, J., 2019 "Supersonic separation technology for natural gas processing: A review, Chem. Eng. Process." 136 (2019) 138-151.

https://doi.org/10.1016/j.cep.2019.01.007.

Song, J., Wang, L., and Chen, LQ., 2010 "The Study on the Application of Nozzle Supersonic Separation Technology in the Dehydration of Gas." JOURNAL OF BEIJING INSTITUTE OF PETRO-CHEMICAL TECHNOLOGY(1):25-30.

https://doi.org/10.3969/j.issn.1008-2565.2010.01.006.

Yang, Y., Shen, SQ., and Kong TY., 2008 "NUMERICAL SIMULATION ON SPONTANEOUS CONDENSATION IN SUPERSONIC STEAM FLOW" JOURNAL OF ENGINEERING THERMOPHYSICS, 29(8): 1393-1396.

Jiang, WM., Liu ZL., and Liu XL., 2010 "INFLUENCES OF EXOTERIC NUCLEI ON VAPOR CONDENSATION FLOWS IN NOZZLE" JOURNAL OF ENGINEERING THERMOPHYSICS, (12):143-146.

Cao, XW., Song, XD., and Bian, J., 2019 "Supersonic dehydrogenation of natural gas with Laval nozzle under different pressures" Cryogenics and Superconductivity, (11). 
Wang, Z., Luo, Y., and Han, ZH., 2012 "Numerical Study on Highspeed Heterogeneous Condensation Flow of Wet Steam" Power Engineering, 32(12):934-940.

https://doi.org/10.3969/j.issn.1674-7607.2012.12.005.

Bian, J., Cao, XW., Yang, W., and Gao, S., and Xiang, CC., 2019 “A new liquefaction method for natural gas by utilizing cold energy and separating power of swirl nozzle", AIChE J. 65 (2019) 16811.

https://doi.org/10.1002/aic.16811.

Gyarmathy G. and Grundlagen einer 1962 "Theorie der Nassdampfturbine" Zürich: Eidgenoessische Technische Hochschule Zuerich,
Sun, WJ., Cao, XW., and Yang, W., 2017 "Study on the Carbon Dioxide Condensation Process in a Laval Nozzle" Acta Petrolei Sinica(Petroleum Processing Section), (04):183-190. https://doi.org/10.3969/j.issn.1001-8719.2017.04.022.

Li, XR., 2002 "Calculating the Density of real gas Using SRK equation" JOURNAL OF OINGDAO INSTITUTE OF CHEMICAL TECHNOLOGY(NATURAL SCIENCE EDIATION), (01):98-100. https://doi.org/10.3969/j.issn.1672-6987.2002.01.025.

$\mathrm{Xu}, \mathrm{XT} ., 2015$ "Study on the law of supersonic natural gas condensation flow" China University of Petroleum (East China).

Wang, SL., and Zhao HJ., 2006 "Design and management of gas transmission pipeline" Chemical Industry Press. 